\title{
The Value of Platelet Volume Parameters and Procalcitonin in the Diagnosis of Neonatal Sepsis
}

Mustafa Mohammed Abdallah ${ }^{1, *}$ MBBCh; Ahmed Mohsen Abdelhakeem² MD; Tarek Abdel-Kareim El-Dahshan ${ }^{3}$ MD ; Sameh Abdelaziz Ahmed ${ }^{2}$ MD.

*Corresponding Author:

Mustafa Mohammed Abdallah

Musbiume@gmail.com

Received for publication June 24, 2021; Accepted July 23, 2021; Published online July 23, 2021.

Copyright The Authors published by Al-Azhar University, Faculty of Medicine, Cairo, Egypt. Users have the right to read, download, copy, distribute, print, search, or link to the full texts of articles under the following conditions: Creative Commons AttributionShare Alike 4.0 International Public License (CC BY-SA 4.0).

doi: 10.21608/aimj.2021.79339.1493

${ }^{1}$ Pediatrics Department, Al-wahat Al-Bahreyah Hospital, Ministry of Health, Giza, Egypt.

${ }^{2}$ Pediatrics Department, Faculty of Medicine, Al-Azhar University, Cairo , Egypt.

${ }^{3}$ Clinical pathology Department, Faculty of Medicine, Al-Azhar University, Cairo , Egypt.

\begin{abstract}
Background: In developing countries, sepsis represents the $3^{\text {rd }}$ cause of neonatal mortality. Procalcitonin and MPV have been studied widely as markers for neonatal sepsis.

Aim of The Work: To evaluate the value of platelet volume parameters compared to procalcitonin as early biomarkers of neonatal sepsis.

Patient and Methods: a prospective case-control study conducted on 80 newborn infants admitted to the university neonatal intensive care unit, Sayed Galal University Hospital, between September and December 2020. Studied neonates have been divided equally into; sepsis, and control groups. Cases were suspected based on clinical presentation, risk factors, and hematological scoring system $(\geq 3)$; and further subdivided into group A: with proven sepsis, and group B: with clinical sepsis. Serum procalcitonin, CRP, blood cultures, and CBC were performed within the $1^{\text {st }} 36$ hours of life.

Results: MPV was higher in both sepsis $(\mathrm{p}<0.0001)$, and culture-proven sepsis groups $(\mathrm{p}=0.00057)$. Other platelet parameters showed no significant difference among sepsis and control groups. Procalcitonin level was higher in both sepsis $(\mathrm{p}<0.00001)$, and culture-proven sepsis groups ( $\mathrm{p}<0.00001$ ). MPV of $\geq 9.54 \mathrm{fL}$, and PCT of $\geq 0.157 \mathrm{ng} / \mathrm{mL}$ cutoff points showed sensitivity, specificity, PPV, and NPV of $(92.5 \%$, $87.5 \%, 88.1 \%, 92.1 \%)$ respectively for MPV, and $(95 \%, 65 \%, 73.1 \%$, 92.9\%) respectively for PCT. MPV showed also positive correlation in sepsis group ( $\mathrm{p}=0.02089,0.03134)$ with PCT and CRP respectively.

Conclusion: MPV and PCT showed close sensitivities, while MPV septicity was even higher. MPV may be considered as a sensitive, affordable, and reliable marker for neonatal sepsis.
\end{abstract}

Keywords: Sepsis; Neonate; Procalcitonin; Platelets.

Disclosure: The authors have no financial interest to declare in relation to the content of this article. The Article Processing Charge was paid for by the authors. Authorship: All authors have a substantial contribution to the article.

\section{INTRODUCTION}

Neonatal sepsis is responsible for about $13 \%$ of all neonatal mortalities and $42 \%$ of deaths during the period from 1-7 days after birth. ${ }^{1}$ It could be classified as early-onset and late-onset according to the age of the newborn at the onset of the sepsis episode. ${ }^{2}$ Researchers have discovered several biomarkers that help us to diagnose and manage sepsis as early as possible. ${ }^{3}$ Procalcitonin (PCT) can differentiate sepsis from healthy control neonates even better than CRP. ${ }^{4}$ The mean volume of platelets is a sensitive and cost-effective marker for neonatal sepsis. $^{6}$

\section{PATIENTS AND METHODS}

This study was conducted between September and December 2020, on 80 newborn infants admitted to the university neonatal intensive care unit, Sayed Galal University Hospital during the period of the study.
Included neonates were 2 groups: Control group (40 neonates) who were healthy, full-term neonates with birth-weight $>2500$ grams. Case group (40 neonates) with neonatal sepsis suspected based on the presence of $\geq 1$ of the following: Clinical signs and symptoms suggesting sepsis such as a poor feeding, lethargy, irritability, respiratory distress, hypotension, and poor perfusion. Laboratory heamtological scoring system of $\geq 3$. History of maternal risk factors such as a chorioamnionitis and PROM $(\geq 18 \mathrm{~h})$, or fetal risk factors such as a prematurity and low birth weight. Case group was further subdivided according to the culture results into: Culture-positive (confirmed) sepsis subgroup (15 neonates), and Culture-negative (clinical) sepsis subgroup (25 neonates). Viral neonatal sepsis due to possible Covid-19 pandemic infection was excluded by excluding infants of Covid-19 PCR positive mothers and infants of suspected mothers based on clinical or radiographic data. Preterm neonates < 34 weeks gestation, newborns with multiple congenital anomalies, intracranial hemorrhage, or suspected to have inborn 
errors of metabolism were also excluded from our study. Gestational age was determined by Ballard score. $^{7}$

Included neonates were subjected to: Full perinatal and family histories. Serial physical examinations since the onset of sepsis. Laboratory investigations: Complete blood count (CBC) done by CELL-DYN 3200 Systems, Serum level of C-reactive protein done by Latex agglutination technique, and serum level of procalcitonin done by ELISA open-system. Blood sampling $(\geq 1 \mathrm{CC}$ ) was performed for blood culture. Lumbar puncture was done only for neonates with neurological symptoms such as a seizures. Chest radiograph was done only for neonates with respiratory presentations such as a tachypnea. Echocardiography was done only for neonates with cardiac presentations such as a murmur. CBC and serum Procalcitonin were performed for all included neonates during the $1^{\text {st }} 36$ hours of life, and within 12 hours from the onset of the sepsis episode in sepsis group. Hematological scoring system ${ }^{5}$ was calculated for all included cases. (Table 1)

\begin{tabular}{|c|c|c|}
\hline Test & Abnormality & Score \\
\hline \multirow[b]{2}{*}{$\begin{array}{l}\text { Total WBC } \\
\text { count }\end{array}$} & $\leq 5 \times 10^{3}$ & 1 \\
\hline & $\begin{array}{c}\geq 25 \times 10^{3} \text { at the } 1^{\text {st }} \text { hour } \\
\text { of life, } \geq 30 \times 10^{3} \text { at } 12-24 \\
\text { hours, or } \geq 21 \times 10^{3} \text { at } \geq \\
24 \text { hours of life. }\end{array}$ & 1 \\
\hline \multirow[b]{2}{*}{$\begin{array}{l}\text { Total PMN } \\
\text { count }\end{array}$} & No any mature PMN. & 2 \\
\hline & $\begin{array}{l}\text { Decreased }(\leq 1800) \text {, or } \\
\text { Increased } \geq 5400 \text { at birth, } \\
14 \times 10^{3} \text { at } 12-48 \text { hours, or } \\
5400 \text { at } \geq 48 \text { hours of life. }\end{array}$ & 1 \\
\hline $\begin{array}{l}\text { Immature } \\
\text { PMN count }\end{array}$ & Increased $(>600)$. & 1 \\
\hline $\begin{array}{l}\text { Immature/ } \\
\text { Total ratio }\end{array}$ & Increased $(>0.120)$. & 1 \\
\hline $\begin{array}{c}\text { Immature/ } \\
\text { Mature ratio }\end{array}$ & 0.3 , or more. & 1 \\
\hline $\begin{array}{l}\text { Degenerative } \\
\text { PMN }\end{array}$ & $\begin{array}{l}\text { Cytoplasmic vacuoles, or } \\
\geq 3 \text { toxic granules. }\end{array}$ & 1 \\
\hline Platelet Count & $\leq 150 \times 10^{3}$. & 1 \\
\hline
\end{tabular}

Table 1: WBC: White blood cells, PMN: Polymorphonuclear cells. Cell count is in Cell $/ \mathrm{mm} 3$.

A score of 2 or less was interpreted as mostly no sepsis, score of 3-4 was a possible sepsis, and score of 5 or more was considered as very likely to have sepsis.

Data was analyzed using IBM SPSS software package 25.0. (NY: IBM). Kolmogorov-Smirnov test verified the normality of the distribution. Descriptive statistics were given. Chi-square test was used to compare different groups for categorical data, and Fisher's exact test was used for the correction of chisquare results if $>20 \%$ of the cells have a count $<5$. We compared parametric quantitative variables between 2 groups using T-test, and ANOVA oneway test has been used if there were $>2$ groups. We also used the Mann-Whitney test to compare nonparametric quantitative variables of 2 groups, while the Kurskal-Wallis test was used when there were > 2 groups. For correlation between 2 variables we used Spearman's correlation coefficient test.

\section{RESULTS}

This study was conducted between September and December 2020, on 80 newborn infants admitted to the NICU, Sayed Galal University Hospital.

In our study, we couldn't find any significant difference between sepsis and control groups as regards sex. However, there was a significant difference as regards gestational age, mode of delivery, birth-weight, NICU admission duration, and PROM duration. (Table 2)

\begin{tabular}{|c|c|c|c|c|c|}
\hline & \multicolumn{2}{|c|}{$\begin{array}{c}\text { Sepsis } \\
\text { neonates } \\
(\text { no. }=40)\end{array}$} & \multicolumn{2}{|c|}{$\begin{array}{c}\text { Control } \\
\text { neonates } \\
(\text { no. }=40)\end{array}$} & \multirow[t]{2}{*}{ P-Value } \\
\hline & No. & $\%$ & No. & $\%$ & \\
\hline Male & 22 & 55 & 21 & 52.5 & \multirow[b]{2}{*}{0.6604} \\
\hline Female & 18 & 45 & 19 & 47.5 & \\
\hline Full-term & 8 & 20 & 40 & 100 & \multirow[b]{2}{*}{$<0.00001 *$} \\
\hline Pre-term & 32 & 80 & 0 & 0 & \\
\hline $\mathrm{CS}$ & 32 & 80 & 22 & 55 & \multirow[b]{3}{*}{$0.0091^{*}$} \\
\hline NVD & 5 & 12.5 & 17 & 42.5 & \\
\hline SVD & 3 & 7.5 & 1 & 2.5 & \\
\hline $\begin{array}{l}\text { Maternal } \\
\text { morbidity }\end{array}$ & 26 & 65 & 8 & 20 & \multirow{2}{*}{1} \\
\hline Mortality & 3 & 7.5 & 0 & 0 & \\
\hline $\begin{array}{l}\text { Birth- } \\
\text { weight } \\
\text { (grams) }\end{array}$ & \multicolumn{2}{|c|}{$1686.18 \pm 656.676$} & \multicolumn{2}{|c|}{$2643.25 \pm 122.336$} & $<0.0001 *$ \\
\hline $\begin{array}{l}\text { PROM } \\
\text { (hours) }\end{array}$ & \multicolumn{2}{|c|}{$22.525 \pm 14.823$} & \multicolumn{2}{|c|}{$7.025 \pm 6.082$} & $<0.00001 *$ \\
\hline
\end{tabular}

Table 2: CS: cesarean section, SVD and NVD: spontaneous and normal vaginal deliveries, NICU: neonatal intensive care unit, PROM: premature rupture of membranes. ${ }^{*}$ : significant at $\mathrm{p} \leq 0.05$.

In our study, a significant difference among sepsis and control groups was found as regards MPV and PCT. However, there was no significant difference as regards other platelet indices. (Table 3 )

\begin{tabular}{|c|c|c|c|}
\hline & $\begin{array}{c}\text { Sepsis } \\
(\text { no. }=40) \\
\text { Mean } \pm \text { SD }\end{array}$ & $\begin{array}{c}\text { Control } \\
(\text { no.=40) } \\
\text { Mean } \pm \text { SD }\end{array}$ & P-value \\
\hline MPV & $\mathbf{1 0 . 5 4 2} \pm \mathbf{0 . 9 6 5}$ & $\mathbf{8 . 6 4 8} \pm \mathbf{0 . 7 3 4}$ & $<\mathbf{0 . 0 0 0 1 *}$ \\
\hline PC & $\mathbf{1 4 4 . 9 4} \pm \mathbf{4 5 . 7 2}$ & $\mathbf{1 6 6 . 2 1} \pm \mathbf{6 4 . 5 9}$ & $\mathbf{0 . 0 9 3 5}$ \\
\hline Plct & $\mathbf{0 . 1 5} \pm \mathbf{0 . 0 4 4}$ & $\mathbf{0 . 1 4 3} \pm \mathbf{0 . 0 5 7}$ & $\mathbf{0 . 4 9 9}$ \\
\hline PDW & $\mathbf{1 8 . 0 9} \pm \mathbf{2 . 9 2 5}$ & $\mathbf{1 7 . 5 0} \pm \mathbf{1 . 2 0}$ & $\mathbf{0 . 2 4 2}$ \\
\hline PCT & $\mathbf{0 . 3 0 2} \pm \mathbf{0 . 1 9 0}$ & $\mathbf{0 . 1 4 4} \pm \mathbf{0 . 0 3 1}$ & $<\mathbf{0 . 0 0 0 0 1 *}$ \\
\hline
\end{tabular}

Table 3: MPV: mean platelet volume. PC: platelet count. Plct: plateletcrit. PDW: platelet distribution width. PCT: Procalcitonin.

In our study, a significant difference among all groups was found as regards MPV and PCT level. However, there was no significant difference as regards other platelet indices. (Table 4) 


\begin{tabular}{|c|c|c|c|c|}
\hline & $\begin{array}{l}\text { Proven sepsis } \\
\qquad(n=15) \\
\text { Mean+SD }\end{array}$ & $\begin{array}{c}\text { Clinical sepsis } \\
\qquad(\mathrm{n}=25) \\
\text { Mean } \pm \text { SD }\end{array}$ & $\begin{array}{c}\text { Control } \\
(n=40) \\
\text { Mean } \pm \text { SD }\end{array}$ & $\mathrm{P}$-value \\
\hline MPV & $9.962 \pm 0.6432$ & $10.889 \pm 0.9678$ & $\begin{array}{c}8.648 \pm \\
0.734\end{array}$ & $<0.00001 *$ \\
\hline $\mathrm{PC}$ & $162.20 \pm 48.20$ & $134.58 \pm 41.75$ & $\begin{array}{c}166.21 \pm \\
64.6\end{array}$ & 0.0784 \\
\hline Plct & $0.16 \pm 0.046$ & $0.145 \pm 0.043$ & $\begin{array}{c}0.143 \pm \\
0.057\end{array}$ & 0.550 \\
\hline$\overline{\text { PDW }}$ & $17.936 \pm 0.966$ & $18.192 \pm 3.65$ & $17.50 \pm 1.20$ & 0.474 \\
\hline PCT & $0.185 \pm 0.014$ & $0.373 \pm 0.212$ & $\begin{array}{c}0.144 \pm \\
0.031\end{array}$ & $<0.00001 *$ \\
\hline
\end{tabular}

\section{Table 4:}

In our study, only MPV showed a significant correlation with PCT level. (Table 5)

\begin{tabular}{|c|c|c|c|c|}
\hline \multirow{2}{*}{} & \multicolumn{2}{|c|}{$\begin{array}{r}\text { Sepsis (PCT) } \\
(\mathrm{n}=40)\end{array}$} & \multicolumn{2}{c|}{$\begin{array}{c}\text { Control (PCT) } \\
(\mathrm{n}=40)\end{array}$} \\
\cline { 2 - 5 } & Rho & P-value & Rho & P-value \\
\hline MPV & $\mathbf{0 . 3 6 4 1 4}$ & $\mathbf{0 . 0 2 0 8 9 *}$ & $\mathbf{0 . 1 0 4 5 2}$ & $\mathbf{0 . 5 2 0 9 7}$ \\
\hline Plct & $\mathbf{- 0 . 1 6 9 8}$ & $\mathbf{0 . 2 9 4 8 9}$ & $\mathbf{0 . 0 0 3 8 2}$ & $\mathbf{0 . 9 8 1 3 5}$ \\
\hline PDW & $\mathbf{0 . 0 6 4 6 4}$ & $\mathbf{0 . 6 9 1 9 1}$ & $\mathbf{0 . 1 5 3 7 7}$ & $\mathbf{0 . 3 4 3 4 8}$ \\
\hline PC & $\mathbf{- 0 . 2 5 9 5 9}$ & $\mathbf{0 . 1 0 5 7 5}$ & $\mathbf{- 0 . 0 4 6 6 2}$ & $\mathbf{0 . 7 7 5 1 2}$ \\
\hline
\end{tabular}

Table 5: Rho: Spearman's correlation test.

In our study, MPV in sepsis groups showed a significant correlation with CRP level. In contrast, correlation between HSS and MPV in the sepsis group was not statistically significant. (Table 6)

\begin{tabular}{|c|c|c|}
\hline \multirow{2}{*}{} & \multicolumn{2}{|c|}{$\begin{array}{c}\text { Sepsis (MPV) } \\
(\mathrm{n}=40)\end{array}$} \\
\cline { 2 - 3 } & Rho & P-value \\
\hline HSS & 0.0164 & 0.919995 \\
\hline CRP & 0.34092 & $0.03134 *$ \\
\hline
\end{tabular}

Table 6: HSS = Hematologic scoring system. CRP = C-reactive protein.

Comparing ROC curves for both MPV and PCT, we found that MPV sensitivity approaches that of PCT with even higher specificity in sepsis cases.(Figure 1)

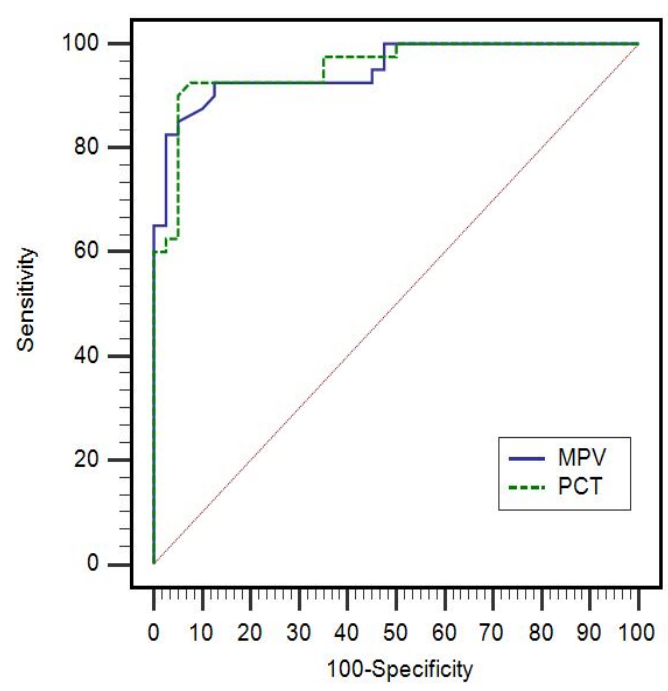

\begin{tabular}{|c|c|c|c|c|c|c|c|c|c|}
\hline \multirow{2}{*}{ Test } & \multirow{2}{*}{ AUC } & \multirow{2}{*}{ SE } & \multicolumn{2}{|c|}{95 CI } & \multirow{2}{*}{ cutoff } & Sensitivity & Specificity & + +PV & -PV \\
\cline { 4 - 9 } & & & Lower & Upper & & & & & \\
\hline PCT & 0.954 & 0.0217 & 0.0882 & 0.988 & $\geq 0.157$ & 95 & 65 & 73.1 & 92.9 \\
\hline MPV & 0.952 & 0.0224 & 0.879 & 0.987 & $\geq 9.54$ & 92.5 & 87.5 & 88.1 & 92.1 \\
\hline
\end{tabular}

Fig. 1: AUC: Area under curve. SE: Standard error of the AUC. CI: Confidence Intervals. +PV and -PV: Positive and negative predictive values

\section{DISCUSSION}

Many researchers have been looking for new markers for neonatal sepsis for several years. In our study, we were looking for a sensitive, cost-effective, and reliable marker that may help us to make the decision of starting antibiotic therapy for bacterial neonatal sepsis. MPV is a sensitive and cost-effective marker of neonatal sepsis. ${ }^{6}$

Included neonates were subjected to the following: Full perinatal and family histories. Serial physical examinations since the onset of sepsis. Laboratory investigations. $\mathrm{CBC}$ and serum Procalcitonin were performed for all included neonates during the $1^{\text {st }} 36$ hours of life, and within 12 hours from the onset of the sepsis in sepsis group.

In our study, as regards the demographic data, there were 43 male neonates [22 (55\%) case, and 21 $(52.5 \%)$ control], and 37 female neonates [18 (45\%) case, and $19(47.5 \%)$ control]. Birth-weight Mean \pm SD was $1686 \pm 656.67$ grams for the case group, and $2643 \pm 122.33$ grams for the control group. Regarding gestational age, neonates were classified as 48 Full-term [8 $(20 \%)$ case, and 40 $(100 \%)$ control], and 32 preterm, all preterm neonates were in the case group (as 80\%). Gestational age was determined by Ballard score. ${ }^{7}$ 
As regards both gestational age and birth-weight, a significant difference between sepsis and healthy neonates was found (P-value of $<0.00001$, and $<0.0001$ respectively) with a higher prevalence of sepsis in preterm, as well as in LBW neonates. This in accordance with Belachew \& Tewabe, who reported that sepsis incidence was higher with both prematurity and low birthweight. ${ }^{8}$

In our study, regarding the mode of delivery, sepsis was more prevalent with cesarean section $(\mathrm{p}$-value= 0.009 ). CS represented $80 \%$ of neonates in sepsis groups $(\mathrm{n}=32)$, and $55 \%$ in control group $(\mathrm{n}=22)$. The percentage of births by CS 2007-2014 in Egypt was $52 \%{ }^{9}$

In our study, $\mathrm{PROM} \geq 18 \mathrm{hr}$ represented a major risk factor for sepsis (p-value <0.00001) in 30 cases (75\%). This is in accordance with Atrolia et al. who reported that PROM is a leading cause of prematurity and neonatal sepsis. ${ }^{10}$

Regarding platelet parameters, according to Go et al., the normal ranges were: PC: $150-450 \times 10^{9} / \mathrm{L}$; MPV: 7.4 - 10.4 fL; PDW: 8.3 - $56.6 \%$; PCT: 0.22$0.24 \%$. Go et al. has conducted a large cohort study that showed no differences in platelet volume parameters at birth between late-preterm and term neonates. ${ }^{11}$ However, previous report by Alicja et al. indicated that platelet count and plateletcrit were lower in late-preterm neonates compared with term neonates. ${ }^{12}$

In our study, Regarding MPV, it was significantly higher in sepsis group than in control group (P-value $<0.0001)$. It was also significantly higher in proven sepsis than in other groups ( $\mathrm{p}$-value $=0.00057$ ). So an MPV value of $\geq 9.54 \mathrm{fL}$ may be considered as a good marker for sepsis. This is in accordance with Hanaganahalli et al. ${ }^{6}$ We noticed that this value was normal for age and may be insignificant alone. Small sample in our study could be the reason.

As regards other platelet indices, we found no significant difference among sepsis and healthy groups with p-values of $(0.499,0.242$, and 0.093$)$ respectively. They also showed the same results for proven sepsis, clinical sepsis, and control groups with p-values of $(0.550,0.474$, and 0.078$)$ for Plct, PDW, and PC respectively.

This is in accordance with Hanaganahalli et al. as regards PDW, but against their results regarding PC and Plct. Hanaganahalli et al. reported that platelet count and plateletcrit were increased in proven sepsis group more than in clinical sepsis and control groups. ${ }^{6}$ We suggest that this is due to the low number of cases in our study and the measurement timing during the early phase of sepsis.

Tayman et al. reported that, in sepsis, PC was observed to decrease while MPV was observed to increase in consecutive measurements. These results were against our results as regards PC which may be explained by their serial measurements against our single measurement. Time allows platelet parameters to be affected during the sepsis process, and this can only be noticed with serial measurements. ${ }^{13}$

As regards normal serum procalcitonin (PCT), Naramura et al. reported that, gestational age (GA) had no significant effect on serum procalcitonin levels during the $1^{\text {st }} 48$ hours of life. In contrast,
Fukuzumi et al. reported that the median level of PCT at day 1 was lower in term and preterm infants than in other preterm neonates. ${ }^{13,14}$

According to Naramura et al., PCT levels at 12-36 hours of life were $0.14-4.39 \mathrm{ng} / \mathrm{mL}$ and $0.15-4.44$ $\mathrm{ng} / \mathrm{mL}$ in term and preterm neonates respectively. These values were < half Fukuzumi et al. results. Naramura et al. excluded the cases of respiratory failure, which causes a rise in PCT level unlike Fukuzumi et al. ${ }^{13,14}$ In our study, we included only late-preterm and term neonates and relayed on Naramura et al. results.

In our study, serum PCT levels in sepsis group were higher than in control group ( $\mathrm{p}$-value $<0.00001)$. It was also higher in proven than in clinical sepsis and control groups (p-value < 0.00001). So the cutoff level of PCT of $\geq 0.157 \mathrm{ng} / \mathrm{mL}$ may be considered as a good marker for neonatal sepsis. This is in accordance with Umran et al. and Aydemir et al. ${ }^{15,16}$ In our study, we found positive correlations between MPV and both PCT level and CRP level in sepsis group. This is in accordance with Tayman et al as regards CRP. We could not find any previous correlation between PCT and MPV. ${ }^{12}$

After comparing the two ROC curves for both MPV and PCT, we found that MPV sensitivity approaches that of PCT with even higher specificity in sepsis cases. Both of them increased in the first few hours from the sepsis onset.

Our aim was to find an ideal screening marker for neonatal sepsis cases in order to minimize the complications of both sepsis and empiric antibiotic treatment.

The ideal screening marker for sepsis would be highly sensitive (to allow early diagnosis), highly specific (to allow appropriate treatment), of low cost (to be affordable), and easily performed (requires a small sample and an easy technique). In our study, many of these criteria were found in both PCT and MPV. MPV was more easily performed, had a lower cost, and a higher specificity for sepsis. However, as the cutoff level of MPV in our study was found to be within the normal range, we suggest it to be added to other screening markers.

Our study had some limitations including: the low number of cases and the single measurement method. We did not choose to do serial measurements due to the high cost and the inappropriate results for the aim, as our aim was to measure the level of PCT and platelet parameters during the early phase of the sepsis process. We thought that serial measurements are useful for prognostic not screening targets, and in that matter, CRP is a very effective marker with a low cost and simple measurement techniques.

\section{CONCLUSION}

The significant results among the studied groups were for both mean platelet volume (MPV), and Procalcitonin (PCT). With close sensitivity in both and a higher specificity of MPV. The cutoff value of $\geq 9.54 \mathrm{fL} \mathrm{MPV}$ and of $\geq 0.157 \mathrm{ng} / \mathrm{mL}$ serum PCT level were considered to have a diagnostic significance in sepsis. However neither one of them 
can be used as a diagnostic marker alone as their cutoff levels are in the normal range for age.

\section{REFERENCES}

1. Zea-Vera A, Ochoa TJ. Challenges in the diagnosis and management of neonatal sepsis. J Trop Pediatr. 2015;61(1):1-13.

2. Shane AL, Sánchez PJ, Stoll BJ. Neonatal sepsis. Lancet. 2017;390(10104):1770-80.

3. Hedegaard SS, Wisborg K, Hvas AM. Diagnostic utility of biomarkers for neonatal sepsis--a systematic review. Infect Dis (Lond). 2015;47(3):117-24.

4. Hahn WH, Song JH, Kim H, Park S. Is procalcitonin to $\mathrm{C}$-reactive protein ratio useful for the detection of late onset neonatal sepsis?. J Matern Fetal Neonatal Med. 2018;31(6):822-6.

5. Narasimha A, Harendra Kumar ML. Significance of Hematological Scoring System (HSS) in Early Diagnosis of Neonatal Sepsis. Indian J Hematol Blood Transfus. 2011;27(1):14-7.

6. Hanaganahalli SB, Sreeram S, Bompada M, Kuppannagari SK, Suresh PK, Philipose CS. Is MPV a Predictive Marker for Neonatal Sepsis? A Pilot Study. J Pediatr Hematol Oncol. 2018;40(7):548-52.

7. Ballard JL, Khoury JC, Wedig K, Wang L, EilersWalsman BL, Lipp R. New Ballard Score, expanded to include extremely premature infants. $J$ Pediatr. 1991;119(3):417-23.

8. Belachew A, Tewabe T. Neonatal sepsis and its association with birth weight and gestational age among admitted neonates in Ethiopia: systematic review and meta-analysis. BMC Pediatr. 2020;20(1):55.

9. Betrán AP, Ye J, Moller AB, Zhang J, Gülmezoglu AM, Torloni MR. The Increasing Trend in Caesarean Section Rates: Global, Regional and National Estimates: 1990-2014. PLoS One. 2016; 11(2):e0148343.

10. Atrolia S, Ekka SC, Tirkey S, Vivek V. Aetiological Factors and Foetomaternal Outcome in PROM. Journal of Evolution of Medical and Dental Sciences. 2020;9(2):91-7.

11. Go H, Ohto H, Nollet KE, Kashiwabara N, Chishiki M, Hoshino M, Ogasawara K, Kawasaki Y, Momoi N, Hosoya M. Perinatal factors affecting platelet parameters in late preterm and term neonates. PLoS One. 2020;15(11): $\mathrm{e} 0242539$.

12. Alicja W, Agnieszka P, Piotr L, Slawomir R, Barbara $\mathrm{KW}$, Milena D, Robert M. Platelet indices in late preterm newborns. J Matern Fetal Neonatal Med. 2017;30(14):1699-703.

13. Catal F, Tayman C, Tonbul A, Akça H, Kara S, Tatli MM, Oztekin O, Bilici M. Mean platelet volume (MPV) may simply predict the severity of sepsis in preterm infants. Clin Lab. 2014;60(7):1193-200.
14. Naramura $T$, Tanaka $K$, Inoue $T$, Imamura $H$, Yoshimatsu H, Mitsubuchi H, Nakamura K, Iwai M. New reference ranges of procalcitonin excluding respiratory failure in neonates. Pediatr Int. 2020;62(10):1151-7.

15. Fukuzumi N, Osawa K, Sato I, Iwatani S, Ishino R, Hayashi N, Iijima K, Saegusa J, Morioka I. Agespecific percentile-based reference curve of serum procalcitonin concentrations in Japanese preterm infants. Sci Rep. 2016;6:23871.

16. Umran, R., M Hashim, J., \& Jameel, H. Significance of Serum Procalcitonin Level in the Early Diagnosis of Neonatal Sepsis. Iranian Journal of Neonatology IJN. 2020; 11(3), 1-6.

17. Aydemir C, Aydemir H, Kokturk F, Kulah C, Mungan AG. The cut-off levels of procalcitonin and C-reactive protein and the kinetics of mean platelet volume in preterm neonates with sepsis. $B M C$ Pediatr. 2018;18(1):253. 